\title{
Molecular Determinants of Skeletal Muscle Hypertrophy in Animals
}

\section{Kunihiro Sakuma ${ }^{1 *}$ and Akihiko Yamaguchi ${ }^{2}$}

${ }^{1}$ Research Center for Physical Fitness, Sports and Health, Toyohashi University of Technology, 1-1 Hibarigaoka, Tenpaku-cho, Toyohashi 441-8580, Japan ${ }^{2}$ School of Dentistry, Health Sciences University of Hokkaido, Kanazawa, Ishikari-Tobetsu, Hokkaido 061-0293, Japan

\begin{abstract}
Beyond skeletal muscle's primary function as a force generator for locomotion, there is a growing recognition of the important role skeletal muscle plays in overall health through its impact on whole-body metabolism as well as directly influencing quality of life issues with chronic disease and aging. Over the last decade, extensive progress has been made with regard to our understanding of the molecules that regulate skeletal muscle mass. Various growth factors such as insulin-like growth factor-I (IGF-I), hepatocyte growth factor (HGF), and leukemia inhibitory factor (LIF) have been shown to stimulate the activation, proliferation, and differentiation of satellite cells, and then contribute to muscle hypertrophy as well as normal muscle growth. In contrast, myostatin inhibits these processes through forkhead box O (FOXO) and/or Smad 2/3-dependent signaling. Intramuscular signaling by PI3-K/Akt/mTOR, calcineurin, and serum response factor (SRF) activates protein synthesis but some signaling also inhibits protein degradation at the same time. Although various studies using in vitro cell cultures and in vivo rodent models have revealed candidates for proteins that modulate the hypertrophic process in muscle fibers after mechanical loading, these findings do not necessarily apply to the adaptations that occur in human muscle. In this review, we discuss several possible factors regulating muscle hypertrophy, and the adaptations of human muscle after resistance training, a model of mechanical loading.
\end{abstract}

Keywords: Skeletal muscle; Hypertrophy; Satellite cell; IGF-I; Myostatin; PGC-1a

\begin{abstract}
Abbreviations: ActRIIB: Activin Receptor IIB; ALK: Activin Receptor-Like Kinase; Atrogin-1: Atrophy Gene-1; CsA: Cyclosporine A; FGF: Fibroblast Growth Factor; FOXO: Forkhead Box O; GSK3 $\beta$ : Glycogen Synthase 3- $\beta$; HGF: Hepatocyte Growth Factor; IGF-I: Insulin-like Growth Factor-I; JAK1: Janus Kinase 1; MEF2: Myocyte Enhancer Factor-2; MHC: Myosin Heavy Chain; MRTF: Mycardin-Related Transcription Factor; mTOR: Mammalian Target of Rapamycin; MuRF: Muscle Ring Finger; NF- $\kappa B$ : Nuclear FactorkappaB; NO: Nitric Oxide; NOS: Nitric Oxide Synthase; p70S6K: 70 kDa Ribosomal Protein S6 Kinase; PGC-1a: Peroxisome ProliferatorActivated Receptor $\gamma$ Coactivator-1 $\alpha$; PI3-K: Phosphatidylinositol 3-Kinase; PPAR: Peroxisome Proliferator-Activated Receptor; RM: Repetition Maximum; SRF: Serum Response Factor; STARS: Striated muscle Activators of Rho Signalng; STAT: Signal Transducers and Activators of Transcription; TGF- $\beta$ : Transforming Growth Factor- $\beta$; TORC1: TOR Signaling Complex 1; TSC-2: Tuberous Sclerosis Complex-2
\end{abstract}

\section{Introduction}

In humans, skeletal muscle is the most abundant tissue in the body comprising 40-50\% of body mass and playing vital roles in locomotion, heat production during periods of cold stress, and overall metabolism. Skeletal muscle is composed of bundles of muscle fibers called fascicles. The cell membrane surrounding the muscle cell is the sarcolemma, and beneath the sarcolemma lies the sarcoplasm, which contains the cellular proteins, organelles, and myofibrils: the titin actin filament and the thicker myosin filament. The arrangement of these protein filaments gives skeletal muscle is striated appearance.

Skeletal muscle is capable of remarkable adaptations in response to altered activity. These adjustments to mechanical and metabolic demands elicit marked modifications of gene expression that could lead to gain (hypertrophy) or loss (atrophy) of muscle mass. Whereas endurance training leads to minor changes in skeletal muscle mass, strength training induces marked hypertrophy of exercising muscles. Histochemical analyses clearly show a 10 to $30 \%$ increase in muscle fiber cross-sectional area after 10-12 weeks of resistance training in sedentary subjects [1].
Satellite cells are resident myogenic stem cells found in postnatal skeletal muscle, accounting for 3-9\% of the sublaminal nuclei associated with adult normal muscle fiber [2], with the variation widely depending on animal species, age, muscle fiber type, and longitudinal location of the cell along the fiber $[3,4]$. Satellite cells, existing between the basal lamina and the sarcolemma of the fiber [5], are normally found in a mitotically and metabolically quiescent or dormant state most of the time in adult muscles [6,7]. When muscle is injured or mechanically stretched, satellite cells activate to enter the cell cycle from a protracted G1 state (often referred to as G0). Activated satellite cells have been shown to migrate to the damaged site where they replicate DNA, divide, differentiate, and fuse with the adjacent muscle fiber or form new fibers $[4,8]$.

It has been reported that satellite cells are activated in compensatory hypertrophy [8,9], and addition of new nuclei to the growing fiber seems to be required for extreme hypertrophy. Since the myonuclear domain is constant in hypertrophied muscle after mechanical overloading $[10,11]$, many satellite cells must be incorporated adjacent to muscle fibers. In fact, irradiation of satellite cells followed by a loading stimulus results in an attenuated increase in skeletal muscle mass and protein content [12]. Therefore, it is necessary for consecutive processes (the activation, proliferation, and differentiation of satellite cells) to elicit muscle hypertrophy in the case of mechanical overloading as well as normal growth. However, several researchers recently suggested satellite cell-independent muscle hypertrophy during mechanical

*Corresponding author: Kunihiro Sakuma, PhD, Research Center for Physical Fitness, Sports and Health, Toyohashi University of Technology, 1-1 Hibarigaoka Tenpaku-cho, Toyohashi, 441-8580, Japan, Tel: 81-532-44-6630; Fax: 81-532-446947; E-mail: ksakuma@las.tut.ac.jp

Received November 21, 2011; Accepted January 12, 2012; Published January 16,2012

Citation: Sakuma K, Yamaguchi A (2012) Molecular Determinants of Skeletal Muscle Hypertrophy in Animals. J Sport Medic Doping Studie S1:002. doi:10.4172/2161-0673.S1-002

Copyright: ( $) 2012$ Sakuma K, et al. This is an open-access article distributed under the terms of the Creative Commons Attribution License, which permits unrestricted use, distribution, and reproduction in any medium, provided the original author and source are credited. 
overloading. In addition, some have debated whether the contribution of satellite cells to fiber hypertrophy in adult muscle is minor [13,14].

In hypertrophied muscle, increasing protein synthesis and decreasing protein degradation are also important events. PI3-K (phosphatidylinositol 3-kinase)/Akt/mTOR (mammalian target of rapamycin) signaling has been shown to be crucial to protein synthesis $[15,16]$. Mechanical stretching in vivo and in vitro activates SRFdependent signaling in skeletal muscle similar to smooth and cardiac muscles $[17,18]$. Although many factors have been shown to influence the hypertrophic process in skeletal muscle, most studies have been conducted using an in vitro culture system $[19,20]$ or rodent muscle $[17,21,22]$. In addition, the adaptations after resistance training would be clearly different to those for mechanical overloading, a common model of rodent muscle hypertrophy. In this review, we summarize possible candidates for proteins that regulate muscle hypertrophy. In addition, we describe recent findings regarding these candidates in human skeletal muscle after resistance training.

\section{Modulators of muscle hypertrophy}

Insulin-like growth factor-I: The anabolic effects of insulin-like growth factor-I (IGF-I) have been demonstrated in both muscle cell lines and in vitro animal models [23-26]. For example, the addition of IGF-I to cultured myotubes results in an enlargement of myotube diameters and a higher protein content $[25,26]$, while the delivery of IGF-I either through osmotic pumps or genetic overexpression results in increased muscular mass in rodents [23,27]. Mechanical loading also results in skeletal muscle synthesis of IGF-I [28-30] in vivo, which has led investigators to conclude that IGF-I is a critical factor involved in skeletal muscle hypertrophy. Resistance training also results in increased IGF-I mRNA expression in human skeletal muscle [31,32]. Pre-training levels of IGF-I expression have been shown to correlate most consistently with the post-training gains of muscle size and strength [33].

IGF-I is thought to induce muscle growth through the increased proliferation of satellite cells and the enhancement of protein translation resulting in an increase in the rate of protein synthesis [34]. In addition to stimulating the proliferation of myoblast proliferation, IGF-I stimulates their differentiation [35]. IGF-I also alters the transcription and translation of muscle factors that regulate myocyte growth or differentiation [36]. For example, IGF-I inhibits production of myogenin, a protein that stimulates muscle cell differentiation, thus allowing increased myoblast proliferation. However, its effects are biphasic because prolonged exposure to IGF-I results in increased myogenin expression, thus facilitating differentiation [37]. IGF-I also modulates the expression of MyoD, myocyte enhancer factor-2 (MEF2) and $\mathrm{p} 21$ to control differentiation.

Many investigators hypothesize that IGF-I expression induced by mechanical overloading is crucial to the hypertrophic process [38-40]. However, several studies indicated earlier activation of mTORC1 than enhancement of PI3-K/Akt [41] or Akt/mTOR activation not through IGF-I receptor-dependent signaling [42]. Although the possibility of IGF-I-dependent muscle hypertrophy after mechanical overloading can not be excluded, further study is needed to elucidate the true role of IGF-I in muscle hypertrophy in vivo.

Hepatocyte growth factor and neuronal nitric oxide synthase: Two factors have been demonstrated to activate quiescent satellite cells. The first is hepatocyte growth factor (HGF). Early experiments using single muscle fibers with associated quiescent satellite cells have shown that growth factors, such as IGF-I and fibroblast growth factor (FGFs), do not activate satellite cells in fibers $[43,44]$. Although IGF-I and FGFs are reported to activate satellite cells, the studies involved typically used cultures of muscle cells that were not quiescent; IGF-I and FGFs increase the proliferative activity of satellite cells once they are activated, even when that activation results during the cell isolation process, i.e. prior to the plating of cells or fibers for culture. Moreover, plateletderived growth factor $\mathrm{BB}$, transforming growth factor- $\beta$ (TGF- $\beta$ ), and epidermal growth factor do not stimulate quiescent cells to enter the cell cycle in vitro $[45,46]$. Therefore, HGF is the only growth factor that has been established to have the ability to stimulate quiescent satellite cells to enter the cell cycle early in a culture assay and in vivo $[47,48]$. HGF is localized to the extracellular domain of un-injured skeletal muscle fibers through a possible association with glycosaminoglycan chains of proteoglycans that are essential components of the extracellular matrix, and following injury, quickly associates with satellite cells [49].

The second component shown to be involved in satellite cell activation is nitric oxide (NO), a short-lived free radical that is well known as a freely diffusible and ubiquitous molecule produced by nitric oxide synthase (NOSs) from the L-arginine of substrates. In skeletal muscle, neuronal NOS (nNOS, also called NOS-1) is localized to the sarcolemma of muscle fibers by association at its amino terminus with alpha1-syntrophin linked to the dystrophin cytoskeleton [50]. The NO radical is normally produced in very low level pulses by muscles under conditions where satellite cells are quiescent [51], and the expression and activity of constitutive NOS (nNOS and eNOS) are up-regulated by exercise, loading injury, shear force, and mechanical stretch. Therefore, the NO radical is an exciting subject in the 'mechanobiology' of skeletal muscles that can respond to mechanical stimuli and initiate the molecular programs that ensure tissue growth, adaptation, and regeneration.

Studies in vitro and in vivo using rodent muscle have shown HGF and NO to regulate the activity of many satellite cells $[48,49,52,53]$ Although several studies have demonstrated an important role for HGF in satellite cells during muscle hypertrophy in vivo, only a few [54,55] have found HGF mRNA expression in the plantaris muscle to be upregulated after functional overload. Just one study has indicated a role for HGF in human hypertrophied muscle. Shelmadine et al. [56] found an increase in the amount of phosphorylated c-Met, the receptor for HGF, after 28 days of resistance training [a program consisting of nine exercises such as bench press, shoulder shrugs, chest flies, biceps curls, i.e., $3 \times 10 \mathrm{RM}$ (repetition maximum), 4 times/week]. Strangely, whether resistance training modulates the expression pattern of HGF in human muscle and/or satellite cells have not been investigated. In contrast, the amount of nNOS mRNA and protein has been demonstrated to be increased in rodent muscles after swim training ( $60 \mathrm{~min}$ twice/day for 3-4 week) [57] and acute eccentric exercise (downhill running) [58] and in human muscle after short-term (10 days) endurance training [59]. Similarly, it is unknown whether resistance training increases nNOS expression in human skeletal muscle. Therefore, the functional role of $\mathrm{HGF}$ and nNOS during muscle hypertrophy in humans needs to be clarified by further studies. It may be that the extent of mechanical stimulation by resistance training affects the expression of HGF and nNOS in human muscle.

Leukemia inhibitory factor: Leukemia inhibitory factor (LIF) is a newly discovered myokine [60], originally identified by its ability to induce the terminal differentiation of myeloid leukemic cells. Today, LIF is known to have a wide array of functions, including acting as a stimulus for platelet formation, the proliferation of hematopoietic cells, bone formation, neural survival and formation, muscle satellite cell proliferation and acute phase production by hepatocytes [61] 
LIF is a long chain four $\alpha$-helix bundle cytokine, which is highly glycosylated and may be present with a weight of $38-67 \mathrm{kDa}$, which can be deglycosylated to $\sim 20 \mathrm{kDa}[62,63]$. Several tissues, including skeletal muscle, express LIF. LIF is constitutively expressed at a low level in type I muscle fibers $[64,65]$ and is implicated in conditions affecting skeletal muscle growth and regeneration [64-66]. Production of the LIF protein is augmented in mechanically overloaded rat plantaris muscle and in denervated rat muscles [65], thus endogenous LIF production is modulated by factors influencing muscle activity. Furthermore, LIF restored the hypertrophic response to increased loading in LIF (-/-) mice, and has been denoted as an important factor in skeletal muscle hypertrophy [67]

In 1991, Austin and co-workers demonstrated that LIF stimulated myoblast proliferation in culture [68], thereby showing that LIF functions as a mitogenic growth factor when added to muscle precursor cells in vitro. To date, different groups have confirmed this finding and shown that LIF induces satellite cell and myoblast proliferation, while preventing premature differentiation, by activating a signaling cascade involving Janus kinase 1 (JAK1), signal transducers and activators of transcription (STAT) 1 and STAT3 [69,70]. In line with this, the specific LIF receptor is primarily expressed by satellite cells and not by mature muscle fibers [64]. Thus, it seems that LIF has the potential to affect satellite cells rather than mature muscle fibers.

Broholm and Pedersen [71] proposed the intriguing hypothesis that the primary function of LIF, as a contraction-induced myokine, is that of a mitogenic growth factor affecting nearby satellite cells in a paracrine fashion. Indeed, in primary human skeletal myocytes, Broholm et al. [60] observed a marked increase in both LIF mRNA and protein in response to a $\mathrm{Ca}^{2+}$ ionophore, ionomycin. Although Broholm et al. [60] also demonstrated that neuromuscular activity caused by endurance exercise ( 3 hours on a cycle ergometer at $~ 60 \%$ of $\mathrm{VO}_{2} \max$ ) elicited LIF mRNA expression in vastus lateralis muscle 0-3 hours postexercise, they did not observe a similar significant increase at the protein level. In contrast, our previous study [65] found that chronic mechanical overloading of rat plantaris muscle induced by ablation of synergists was followed by an increase in LIF protein from 2 to 14 days of overload. Broholm et al. [60] proposed that repetitive bouts of exercise are necessary to induce accumulation of the LIF protein in skeletal muscle. This may be supported by our finding that no LIF protein was detected in hypertrophied muscle on the first day [65]. It is unknown whether increased neuromuscular activity after resistance training up-regulates LIF mRNA and protein expression in human skeletal muscle. The functional role of LIF during muscle hypertrophy needs to be clarified further.

Myostatin and follistatin: Myostatin was first discovered during screening for novel members of the TGF- $\beta$ superfamily, and shown to be a potent negative regulator of muscle growth [72]. Like other TGF- $\beta$ family members, myostatin is synthesized as a precursor protein that is cleaved by furin proteases to generate the active C-terminal dimer. When produced in Chinese hamster ovary cells, the C-terminal dimer remains bound to the $\mathrm{N}$-terminal propeptide, which remains in a latent, inactive state $[73,74]$. Most, if not all, of the myostatin protein that circulates in blood also appears to exist in an inactive complex with a variety of proteins, including the propeptide [75]. The latent form of myostatin seems to be activated in vitro by dissociation of the complex with either acid or heat treatment $[74,75]$ or by proteolytic cleavage of the propeptide with members of the bone morphogenetic protein-1/ tolloid family of metalloproteases [73].

Studies indicate that myostatin inhibits cell cycle progression and reduces levels of myogenic regulatory factors, thereby controlling myoblastic proliferation and differentiation during developmental myogenesis [76-78]. Mutations in myostatin can lead to massive hypertrophy and/or hyperplasia in developing animals [76]. Therefore, many researchers have focused on inhibiting myostatin for treating various muscle wasting disorders such as muscular dystrophy, sarcopenia, and cachexia $[79,80]$. Myostatin binds to and signals through a combination of Activin IIA/B receptors on the cell membrane, but has higher affinity for ActRIIB. On binding to ActRIIB, myostatin forms a complex with a second surface type I receptor, either activin receptor-like kinase (ALK4 or ActRIB) or ALK5 to stimulate the phosphorylation of receptor Smad and the Smad2/3 transcription factors in the cytoplasm. Then $S \operatorname{mad} 2 / 3$ are translocated and modulate the nuclear transcription of genes such as the MyoD gene [81]. In contrast, forkhead box O (FOXO) 1 and Smad2 appear to control the differentiation of $\mathrm{C} 2 \mathrm{C} 12$ myoblasts by regulating myostatin mRNA and its promoters [81]. More recently, the IGF-I-Akt-mTOR pathway, which mediates both differentiation in myoblasts and hypertrophy in myotubes, has been shown to inhibit myostatin-dependent signaling. Blockade of the Akt-mTOR pathway, using siRNA to RAPTOR, a component of TORC1 (TOR signaling complex 1), facilitates myostatin's inhibition of muscle differentiation because of an increase in Smad2 phosphorylation [82]. In contrast, Smad2/3 inhibition promotes muscle hypertrophy partially dependent on mTOR signaling [83].

Considerable progress has been made in terms of understanding how myostatin activity is regulated extracellularly by binding proteins [84]. One of these regulatory proteins is follistatin, which can act as a potent myostatin antagonist. Follistatin has been shown capable of blocking endogenous myostatin activity in vivo, as transgenic mice overexpressing follistatin specifically in skeletal muscle exhibited dramatic increases in muscle growth comparable to those seen in myostatin-knockout mice $[73,85]$. More recently, Hansen et al. [86] conducted acute exercise using a bicycle or one-legged knee extensor exercise for healthy subjects, and acute swimming (1 hour) for mice. They found that the plasma follistatin level increased after acute exercise in all cases. Interestingly, their Western blotting and real-time PCR analysis results showed marked increases in follistatin mRNA and protein in the liver but not skeletal muscle of the mice. Since the up-regulation in liver was lost by the modulation of plasma epinephrine, Hansen et al. [86] proposed muscle-liver cross talk during exercise. Jensky et al. [87] also reported that the amount of follistatin as well as myostatin mRNA did not change after single-leg maximal eccentric or concentric isokinetic knee extension exercise for young women. Many previous studies demonstrated a marked reduction of myostatin expression with resistance training [88-92], although some studies have failed to obtain a positive effect $[93,94]$. More recently, Dennis et al. [33] showed that higher myostatin transcript levels at baseline were predictive of positive training outcomes, which supports the "novel paradox" proposed by Kim et al. [90], whereby individuals with higher baseline levels of the "antigrowth factor" myostatin have greater potential for muscle growth. Myostatin downregulation after acute exercise was strongly associated with muscle mass gains after training [95], and the magnitude of myostatin suppression by training was strongly related to strength gains [33].

\section{Intracellular modulators}

PI3-K-Akt-mTOR: A central pathway involved in hypertrophy is regulated at the translational level by serine/threonine kinase Akt (or $\mathrm{PKB})$. In muscle, Akt is activated by the upstream PI3-K, induced either by receptor binding or by integrin-mediated activation of focal adhesion kinase, such as in cardiac myocytes [96,97]. PI3-K activates Akt, which 
then has the ability to phosphorylate and change the activity of many signaling molecules. Among these are the mTOR and glycogen synthase $3-\beta$ (GSK-3 $\beta$ ), which play a crucial role in the regulation of translation [98]. Akt activates mTOR via phosphorylation and inactivation of tuberous sclerosis complex-2 (TSC-2) [99]. Subsequently, mTOR phosphorylates and activates the $70 \mathrm{kDa}$ ribosomal protein S6 kinase (p70S6K), which results in increased translation either directly or indirectly by activating initiation and elongation factors, eIF-2, eIF-4E (through 4E-BP) and eEF-2 [21]. In addition, Akt also phosphorylates and inactivates GSK-3 $\beta$, thereby activating translation via initiation factor eIF-2B [100]. Other functions of Akt include the negative regulation of protein degradation via inhibition of FOXO-mediated proteasomal activity [101]. However, Akt has also been associated with up-regulation of the proteasome through activation of nuclear factor$\kappa \mathrm{B}(\mathrm{NF}-\kappa \mathrm{B})$ in a PI3-K-dependent process [102].

Several researchers have investigated the adaptive changes in Akt-mTOR-p70S6K signaling after resistance training [103-106]. For example, Mascher et al. [105] had male subjects ( $23 \pm 1$ year) conduct resistance exercise composed of four sets of 10 repetitions at a workload corresponding to $\sim 80 \%$ of $1 \mathrm{RM}$, and conducted muscle biopsies before and $15 \mathrm{~min}, 1 \mathrm{~h}$, and $2 \mathrm{~h}$ after the exercise. They found several fold increases in the phosphorylation of mTOR at Ser ${ }^{2448}$, p70S6K at Ser ${ }^{424} /$ $\mathrm{Thr}^{421}$ and $\mathrm{Thr}^{389}$, and ribosomal protein S6, which persisted for up to $2 \mathrm{~h}$ of recovery. Eight weeks of resistance training (leg presses, squats, and leg extensions) has been shown to increase the phosphorylation (activation) of Akt-1 at Ser ${ }^{473}$, and mTOR at Ser ${ }^{2448}$, but not p70S6K at $\mathrm{Thr}^{389}[104]$. Although it was not determined whether such activation is attributable to IGF-I induced by resistance exercise or solely mechanical signaling not via IGF-I, Akt-mTOR-p70S6K signaling appears to play a central role in exercise-induced muscle hypertrophy.

Calcineurin: During hypertrophy, the binding of IGF-I to its receptor initiates a cascade of signaling events, which result in muscle growth. The major pathway believed to be involved in the onset of hypertrophy is $\mathrm{PI} 3-\mathrm{K} / \mathrm{Akt} / \mathrm{mTOR} / \mathrm{p} 70 \mathrm{~S} 6 \mathrm{~K}$, as eloquently reviewed by Glass $[15,16]$. Recently however, a $\mathrm{Ca}^{2+}$-dependent pathway and its downstream mediators have also been implicated in the adaptive responses seen during hypertrophy. It has been demonstrated that inhibition of calcineurin by cyclosporine A (CsA) results in inhibition of the rapid growth of all fiber types in the overloaded muscle of the mouse [107] through the downstream targets myogenin, utrophin A, the Id family, and myostatin [108-112].

The potent effect of calcineurin upon hypertrophy has further been demonstrated in cell culture. In cell lines, which received CsA, satellite cell differentiation was inhibited. Conversely, in cells administered a constitutively active calcineurin, the differentiation process was enhanced [113]. These results would suggest that calcineurin-dependent signaling is capable of directly targeting satellite cells. However, while satellite cell activity is undoubtedly of importance in overload-related muscle adaptations, it does not appear to be dependent solely upon calcineurin activity [114].

Calcineurin-dependent signaling has been shown to a major modulator for the hypertrophy in slow-type soleus muscle [115-117]. During muscular hypertrophy in vivo, potential downstream targets for the effects of calcineurin are myostatin and MEF2C. Studies in mice have found decreased myostatin mRNA levels in animals with compromised calcineurin signaling compared to wild-type controls [118]. The hypertrophy-defective soleus muscle treated with CsA possessed a lower level of the MEF2C but not MEF2D protein in the subsarcolemmal region in a group of myotubes and/or myofibers during an active-differentiation period (4 days postsurgery) [119]. Two recent findings $[120,121]$ clearly showed that MEF2C is required for thick filaments to form in nascent muscle fibers and for the integrity of the sarcomere and M-line during postnatal muscle growth, by directly regulating several muscle structural genes such as the genes for myomesin, myosin heavy chain (MHC) and myosin light chain.

Endurance training has been shown to increase the expression of calcineurin and calcineurin-downstream candidates [122-124], whereas it has not been studied until recent years whether resistance training modulates calcineurin expression levels in mammalian skeletal muscles. Using twenty-nine physically active male subjects, Lamas et al. [125] tested whether the hypertrophy of skeletal muscle caused by strength and power training included an increase in calcineurin expression. In their study, the strength group trained with an intensity of between 10 and $4 \mathrm{RM}$, while the power training group trained with an intensity of between $30 \%$ and $60 \%$ of 1 RM. Eight-week progressive training regimens elicited a significant increase in strength and muscle fiber hypertrophy, but there was no change in calcineurin mRNA levels in the vastus lateralis muscle after the training. This data may support our hypothesis of a limited role for calcineurin in the hypertrophy of slow-type soleus muscle.

Serum response factor-dependent signaling: Serum response facotr (SRF) is a ubiquitously expressed member of the MADS (MCM1, Agamous, Deficiens, SRF) box transcription factor family, sharing a highly conserved DNA-binding/dimerization domain, which binds the core sequence of SRF/CArG boxes [CC (A/T)6 GG] as homodimers [126]. Functional CArG boxes have been found in the cisregulatory regions of various muscle-specific genes, such as the skeletal $a$-actin [127], muscle creatine kinase, dystrophin, tropomyosin, and myosin light chain $1 / 3$ [128] genes. SRF-dependent signaling plays a major role in a variety of physiological processes, including cell growth, migration, and cytoskeletal organization [129]. Recent results obtained with specific SRF knockout models by the Cre-LoxP system, emphasize a crucial role for SRF in postnatal skeletal muscle growth and regeneration by modulating interleukin-4 and IGF-I mRNA expression [130]. SRF also enhances the hypertrophic process in muscle fibers after mechanical overloading $[17,22]$. For example, we showed that in mechanically overloaded plantaris muscle of rats, the SRF protein co-localized with MyoD and myogenin in myoblast-like cells during the active differentiation phase [22].

It is proposed that the transcriptional activity of SRF is regulated by muscle ring finger (MuRF)-2 [131] and striated muscle activators of Rho signalng (STARS) [132,133]. At the M-band, the mechanically modulated kinase domain of titin interacts with a complex of the protein products of the atrogenes NBR1, p62/SQSTM-1 and the MuRFs $[131,134]$. This complex dissociates under mechanical arrest, and MuRF-1 and MuRF-2 translocate to the cytoplasm and the nucleus [131,135]. One of the probable nuclear targets of MuRFs is SRF [131], suggesting that the MuRF-induced nuclear export and transcriptional repression of SRF may contribute to amplifying the transcriptional atrophy program [136].

Thus, it is possible that the synergistic transactivation of SRF and SRF-linked molecules is abrogated by MuRF-2 in vivo. On the other hand, SRF activity is exquisitely sensitive to the state of actin polymerization. G-actin monomers inhibit SRF activity, whereas polymerization of actin in response to serum stimulation and RhoA signaling. In this pathway, signal inputs lower the ratio of globular actin to fibrillar actin thereby liberating the binding of myocardinrelated transcription factor-A (MRTF-A) to globular actin resulting 
in the nuclear accumulation of MRTF-A and subsequent SRFdependent gene expression [137]. It has been well established that the overexpression of STARS contribute to the nuclear translocation of MRTF-A and MRTF-B $[133,138]$, and then these factors activate SRF transcription.

Lamon et al. [139] demonstrated that 8 weeks of resistance training (leg presses, squats, leg extensions) induced increases in SRF mRNA (3-fold) and nuclear protein (1.25-fold) in the vastus lateralis muscle. In the same training period, they also observed a similar increase in the mRNA levels of several SRF-target molecules ( $\alpha$-actin [127], MHC IIa [140], and IGF-I [130]). They proposed the induction of these molecules by SRF in human hypertrophied muscle, though they did not provide any direct evidence such as transcriptional activation by increased binding of SRF to these SRF-targeted promoter regions. Figure 1 provides an overview of various regulators for both protein synthesis and the participation of satellite cells in hypertrophied muscle after mechanical loading.

PGC-1a: Peroxisome proliferator-activated receptor (PPAR)- $\gamma$ coactivator-1a (PGC-1 $\alpha$ ) was originally identified as a transcriptional co-activator of PPAR- $\gamma$ induced by cold exposure in brown adipose tissue [141]. It has since been shown to co-activate several nuclear hormone receptors and transcription factors (e.g. estrogen-related receptora, PGC-1 $\alpha$, nuclear respiratory factor-1, and MEF-2) which leads to an up-regulation of mitochondrial gene expression and an increase in mitochondrial DNA in tissues such as skeletal muscle [142]. The expression of PGC-1 $\alpha$ in skeletal muscle is greatly influenced by levels of physical activity with endurance exercise increasing PGC-1 $\alpha$ expression [143] and physical inactivity leading to decreased expression [144].

PGC-1 $\alpha$ has been implicated in the regulation of skeletal muscle mass, particularly under conditions of muscle atrophy [145]. For example, PGC-1 $\alpha$ expression decreases in a multitude of different muscle atrophic models [145-149], although some models have shown increases in PGC-1a expression [150,151]. Recently, it was proposed that a decrease in PGC-1 $1 \alpha$ mRNA, prior to the induction of denervation-induced muscle atrophy, may contribute to ensuing

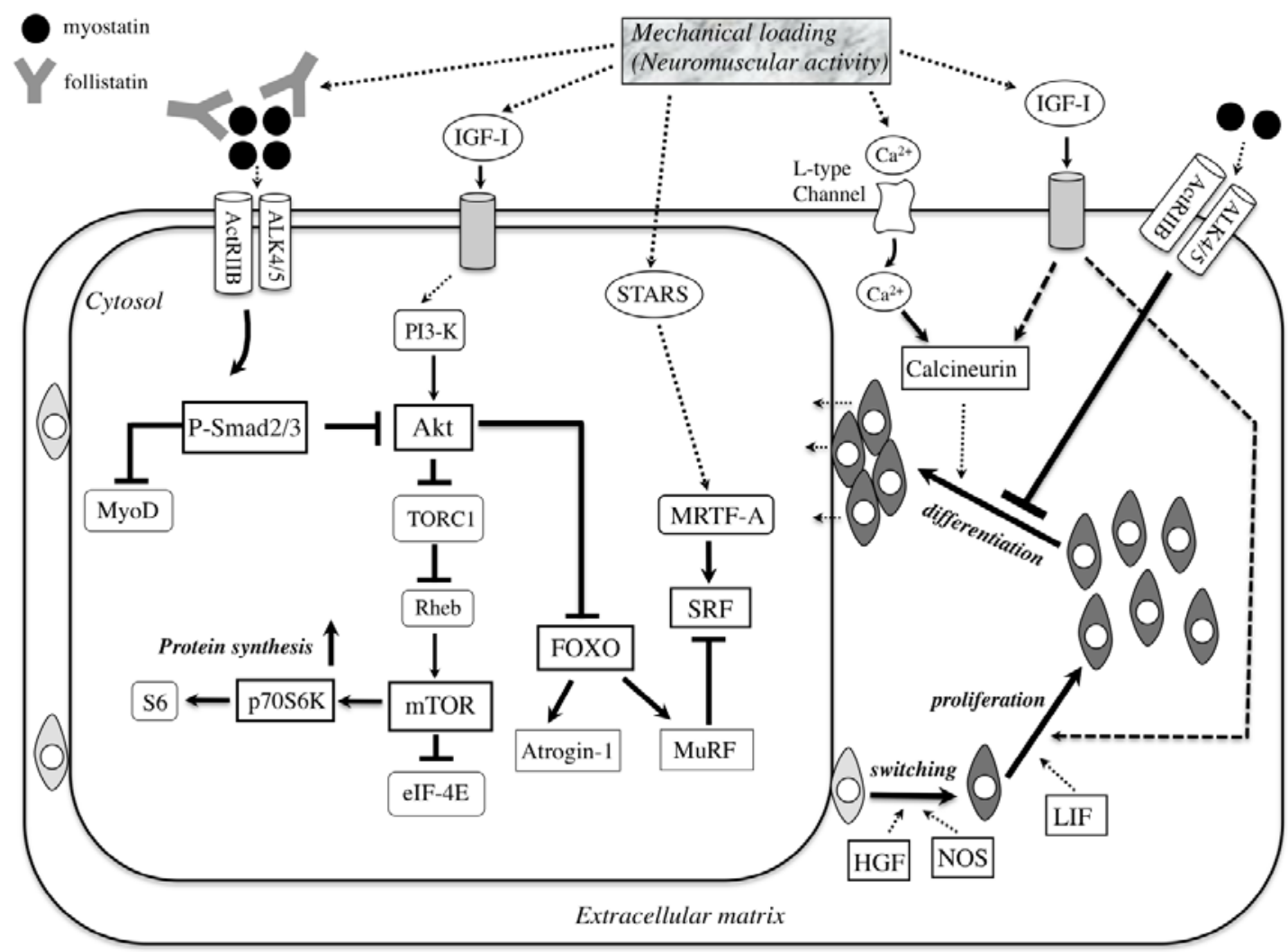

Figure 1: Myostatin signals through the ActRIIB-ALK4/5 heterodimer activate Smad2/3 with blocking of MyoD transactivation in an autoregulatory feedback loop. In addition, Smad3 sequesters MyoD in the cytoplasm to prevent it from entering the nucleus and activating the stem cell population. Recent findings [82,83] suggest that myostatin-Smad pathway inhibit protein synthesis probably due to blocking the functional role of Akt. Mechanical loading (neuromuscular activity) upregulates the amount of follistatin, a myostatin blocker, and of IGF-I and then stimulates protein synthesis by activating Akt/mTOR/p70S6K pathway. Akt blocks the nuclear translocation of FOXO to inhibit the expression of Atrogin-1 and MuRF and the consequent protein degradation. Myosin-actin interaction by mechanical loading activate STARS / MRTF-A/SRF signaling [133]. In contrast, accumulation of MuRF in muscle tissue under inactivity (hindlimb suspension, immobilization, etc) inhibits SRF-dependent transcription of muscle-specicfic genes [131]. HGF and nNOS co-ordinately regulate switching of satellite cells from quiescence to activation. IGF-I and LIF enhance proliferaion of satellite cells. After stimulating by both $\mathrm{Ca}^{2+}$ and IGF-I, calcineurin promote the differentiation of these cells through MyoD, myogenin, and MEF2 [110]. These calcineurin's function during differentiation is abrogated by myostatin-dependent signaling. In hypertrophic muscle after mechanical overloading, the differentiating myotubes seems to be incorporated to the existing muscle fibers ultimately. ActRIIB; activin receptor IIB, ALK4/5; activin-like kinase 4/5, elF4E; eukaryotic initiation factor 4E, FOXO; Forkhead box O, HGF; hepatocyte growth factor, IGF-I; insulin-like growth factor-I, LIF; leukemia inhibitory factor, MRTF-A; mycardin-related transcription factor-A, mTOR; mammalian target of rapamycin, MuRF; muscle ring-finger protein, NOS; nitric oxide synthase, PI3-K; phosphatidylinositol 3-kinase, Rheb; Ras homolog enriched in brain, SRF; serum response factor, STARS; striated muscle activators of Rho signalng, TORC1; a component of TOR signaling complex 1 
muscle atrophy [145]. To date, however, no studies have demonstrated that a decrease in muscle- specific knockout of PGC-1a does not exacerbate denervation-induced atrophy, nor increase the expression of atrogin-1 and MuRF-1 [152]. Thus, notwithstanding potential compensatory adaptations in these transgenic models, to date, there is little support for the hypothesis that the loss of PGC-1a expression per se is sufficient to induce muscle atrophy.

Significant evidence exists that increased expression of PGC-1a is sufficient to inhibit increases in protein degradation and protect skeletal muscle mass from various atrophic stimuli. For example, transient overexpression of PGC-1 1 in vivo blocks c.a.-FOXO3-induced muscle fiber atrophy, and transgenic muscle-specific PGC-1a overexpression protects against denervation- and fasting-induced atrophy, an effect associated with a blunting of the expression of atrogin-1, MuRF1 and cathepsin L [145]. Moreover, PGC-1 $\alpha$ overexpression also protects aging muscle from sarcopenia and is associated with reduced apoptotic markers and suppression of autophagy and ubiquitin-proteasome system genes [153]. The anti-atrophic effects of PGC-1 $\alpha$ may be due, at least in part, to the suppression of FOXO3's binding to, and activation of, genes such as the atrogin-1 gene $[145,146,154]$. NF- $\kappa B$, a transcription factor also implicated in skeletal muscle atrophy $[155,156]$, has recently been shown to be profoundly inhibited by PGC-1a overexpression in vivo [145], which could explain some of the PGC-1a's effect.

\section{Summary}

Studies of muscle biology using cell culture and rodent muscles over the past decade have advanced our understanding of the functionl role of mechanical loading in skeletal muscle hypertrophy. However, these findings do not always correspond to human muscle adaptations after resistance training. PI3-K-Akt-mTOR signaling seems to be crucial to muscle hypertrophy after both mechanical loading in rodents and resistance training in humans irrespective of IGF-Idependent pathways. Although in rodents, HGF and LIF are wellknown mediators for switching, activating or increasing the number of satellite cells during muscle hypertrophy, it needs to be demonstrated whether these factors function similarly in human muscle after resistance training. The induction of PGC-1 $\alpha$ expression by gene manipulation has been shown to prevent age-related muscle wasting in mice. Currently, resistance training with or without amino acids is used not only to promote muscle hypertrophy in young athletes but also to prevent age-related muscle wasting and weakness. It remains to be elucidated whether resistance training-induced PGC-1 $\alpha$ expression increases muscle mass in the young or elderly.

\section{Acknowledgements}

This work was supported by a research Grant-in-Aid for Scientific Research C (No. 23500778) from the Ministry of Education, Science, Culture, Sports, Science and Technology of Japan.

\section{References}

1. Staron RS, Leonardi MJ, Karapondo DL, Malicky ES, Falkel JE, et al. (1991) Strength and skeletal muscle adaptations in heavy-resistance-trained women after detraining and retraining. J Appl Physiol 70: 631-640.

2. Moss FP, Leblond CP (1971) Satellite cells as the source of nuclei in muscles of growing rats. Anat Rec 170: 421-435.

3. Allen RE, Goll DE (2003) Cellular and developmental biology of skeleta muscle as related to muscle growth. In: Scanes CG (ed.), Biology of Growth of Domestic Animals, pp. 148-169, lowa State Press, Ames, lowa.

4. Bischoff $R$ (1994) The satellite cell and muscle regeneration. In: Engel AG Franzini-Armstrong C (eds), Myology, $2^{\text {nd }}$ edn, pp. 97-118, McGraw-Hill, New York.
5. Mauro A (1961) Satellite cell of skeletal muscle fibers. J Biophys Biochem Cyto 9: 493-495.

6. Fukada S, Uezumi A, Ikemoto M, Masuda S, Segawa M, et al. (2007) Molecular signature of quiescent satellite cells in adult skeletal muscle. Stem Cells 25 2448-2459.

7. Schultz E, Gibson MC, Champion T (1978) Satellite cells are mitotically quiescent and activated mouse skeletal muscle: an EM and radioautographic study. J Exp Zool 206: 451-456.

8. McCormick KM, Schultz E (1992) Mechanisms of nascent fiber formation during avian skeletal muscle hypertrophy. Dev Biol 150: 319-334.

9. Schiaffino S, Bormioli SP, Aloisi M (1976) The fate of newly formed satellite cells during compensatory muscle hypertrophy. Virchows Arch B Cell Pathol 21: 113-118.

10. Allen DL, Roy RR, Edgerton VR (1999) Myonuclear domains in muscle adaptation and disease. Muscle Nerve 22: 1350-1360.

11. Roy RR, Monke SR, Allen DL, Edgerton VR (1999) Modulation of myonuclear number in functionally overloaded and exercised rat plantaris fibers. $J$ App Physiol 87: 634-642.

12. Rosenblatt JD, Parry DJ (1992) Gamma irradiation prevents compensatory hypertrophy of overloaded mouse extensor digitorum longus muscle. J App Physiol 73: 2538-2543.

13. McCarthy JJ, Esser KA (2007) Counterpoint: Satellite cell addition is not obligatory for skeletal muscle hypertrophy. J Appl Physiol 103: 1100-1102.

14. Rehfeldt C (2007) Satellite cell addition is/is not obligatory for skeletal muscle hypertrophy. J Appl Physiol 103: 1104.

15. Glass DJ (2005) Skeletal muscle hypertrophy and atrophy signaling pathway. Int J Biochem Cell Biol 37: 1974-1984.

16. Glass DJ (2010) PI3 kinase regulation of skeletal muscle hypertrophy and atrophy. Curr Top Microbiol Immunol 346: 267-278.

17. Gordon SE, Flück M, Booth FW (2001) Skeletal muscle focal adhesion kinase paxillin, and serum response factor and loading dependent. J Appl Physiol 90 1174-1183.

18. Sakuma K, Yamaguchi A (2011) Serum response factor (SRF)-dependent pathway: Potential mediators of growth, regeneration, and hypertrophy of skeletal muscle. Recent Res Devel Life Sci, $5^{\text {th }}$ edn, in press, Research Signpost, Kerala, India

19. Cheema U, Brown R, Mudera V, Yang SY, McGrouther G, et al. (2005) Mechanical signals and IGF-I gene splicing in vitro in relation to development of skeletal muscle. J Cell Physiol 202: 67-75.

20. Perrone CE, Fenwick-Smith D, Vandenburgh HH (1995) Collagen and stretch modulate autocrine secretion of insulin-like growth factor-1 and insulin-like growth factor binding proteins from differentiated skeletal muscle cells. J Bio Chem 270: 2099-2106

21. Bodine SC, Stitt TN, Gonzalez M, Kline WO, Stover GL, et al. (2001) Akt/mTOR pathway is a crucial regulator of skeletal muscle hypertrophy and can prevent muscle atrophy in vivo. Nat Cell Biol 3: 1014-1019.

22. Sakuma K, Nishikawa J, Nakao R, Nakano H, Sano M, et al. (2003) Serum response factor plays an important role in the mechanically overloaded plantaris muscle of rats. Histochem Cell Biol 119: 149-160.

23. Adams GR, McCue SA (1998) Localized infusion of IGF-I results in skeletal muscle hypertrophy in rats. J Appl Physiol 84: 1716-1722.

24. Chakravarthy MV, Davis BS, Booth FW (2000) IGF-I restores satellite cell proliferative potential in immobilized old skeletal muscle. J Appl Physiol 89 1365-1379.

25. Rommel C, Bodine SC, Clarke BA, Rossman R, Nunez L, et al. (2001) Mediation of IGF-I-induced skeletal myotube hypertrophy by $\mathrm{PI}_{3} \mathrm{~K} / \mathrm{Akt} / \mathrm{mTOR}$ and $\mathrm{PI}_{3} \mathrm{~K} / \mathrm{Akt} / \mathrm{GSK} 3$ pathways. Nat Cell Biol 3: 1009-1013.

26. Vyas DR, Spangenburg EE, Abraha TW, Childs TE, Booth FW (2002) GSK-3ß negatively regulates skeletal myotube hypertrophy. Am J Physiol Cell Physio 283: C545-551.

27. Musaró A, McCullagh K, Paul A, Houghton L, Dobrowolny G, et al. (2001) Localized Igf-1 transgene expression sustains hypertrophy and regeneration in senescent skeletal muscle. Nat Genet 27: 195-200.

28. Devol DL, Rotwein P, Sadow JL, Novakofski J, Bechtel PJ (1990) Activation of 
insulin-like growth factor gene expression during work-induced skeletal muscle growth. Am J Physiol 259: E89-95.

29. Sakuma K, Watanabe K, Totsuka T, Uramoto I, Sano M, et al. (1998) Differential adaptations of insulin-like growth factor-I, basic fibroblast growth factor, and leukemia inhibitory factor in the plantaris muscle of rats by mechanical overloading: an immunohistochemical study. Acta Neuropathol 95: 123-130.

30. Yang S, Alnaqeeb M, Simpson H, Goldspink G (1996) Cloning and characterization of an IGF-I isoform expression in skeletal muscle subjected to stretch. J Muscle Res Cell Motil 17: 487-495.

31. Bamman MM, Petrella JK, Kim JS, Mayhew DL, Cross JM (2007) Cluste analysis tests the importance of myogenic gene expression in skeletal muscle during myofiber hypertrophy in humans. J Appl Physiol 102: 2232-2239.

32. Willborn CD, Taylor LW, Greenwood M, Kreider RB, Willoughby DS (2009) Effects of different intensities of resistance exercise on regulators of myogenesis. J Strength Cond Res 23: 2179-2187.

33. Dennis RA, Zhu H, Kortebein PM, Bush HM, Harvey JF, et al. (2009) Muscle expression of genes associated with inflammation, growth, and remodeling is strongly correlated in older adults with resistance training outcomes. Physio Genomics 38: 169-175

34. Adams GR (2002) Invited Review: Autocrine/paracrine IGF-I and skeleta muscle adaptation. J Appl Physiol 93: 1159-1167.

35. Adi S, Bin-Abbas B, Wu NY, Rosenthal SM (2002) Early stimulation and late inhibition of extracellular signal-regulated kinase $1 / 2$ phosphorylation by IGF-I: a potential mechanism mediating the switch in IGF-I action on skeletal muscle cell differentiation. Endocrinology 143: 511-516.

36. Jacquemin V, Butler-Browne GS, Furling D, Mouly V (2007) IL-13 mediates the recruitment of reserve cells for fusion during IGF-1-induced hypertrophy of human myotubes. J Cell Sci 120: 670-681.

37. Tureckova J, Wilson EM, Cappalonga JL, Rotwein P (2001) Insulin-like growth factor-mediated muscle differentiation: collaboration between phosphatidylinositol 3-kinase-Akt-signaling pathways and myogenin. J Biol Chem 276: 39264-39270.

38. Clemmons DR (2009) Role of IGF-I in skeletal muscle mass maintenance. Trends Endocrinol Metabol 20: 349-356.

39. Gundersen K (2011) Excitation-transcription coupling in skeletal muscle: the molecular pathways of exercise. Biol Rev Camb Philos Soc 86: 564-600.

40. Philippou A, Maridaki M, Halapas A, Koutsilieris M (2007) The role of the insulinlike growth factor 1 (IGF-1) in skeletal muscle physiology. In Vivo 21: 45-54.

41. Miyazaki M, McCarthy JJ, Fedele MJ, Esser KA (2011) Early activation of mTORC1 signalling in response to mechanical overload is independent of phosphoinositide 3-kinase/Akt signalling. J Physiol 589: 1831-1846.

42. Spangenburg EE, Roith DL, Ward CW, Bodine SC (2008) A functional insulinlike growth factor receptor is not necessary for load-induced skeletal muscle hypertrophy. J Physiol 586: 283-291.

43. Bischoff $R$ (1986) A satellite cell mitogen from crushed adult muscle. Dev Bio 115: $140-147$.

44. Bischoff R (1990) Cell cycle commitment of rat muscle satellite cells. J Cell Bio 111: 201-207.

45. Bischoff R (1986) Proliferation of muscle satellite cell on intact myofibers in culture. Dev Biol 115: 129-139.

46. Johnson SE, Allen RE (1995) Activation of skeletal satellite cells and the role of fibroblast growth-factor receptors. Exp Cell Res 219: 449-453.

47. Allen RE, Temm-Grove CJ, Sheehan SM, Rice G (1997) Skeletal muscle satellite cell cultures. Methods Cell Biol 52: 155-176.

48. Tatsumi R, Anderson JE, Nevoret CJ, Halevy O, Allen RE (1998) HGF/SF is present in normal adult skeletal muscle and is capable of activating satellite cells. Dev Biol 194: 114-128.

49. Anderson JE (2000) A role for nitric oxide in muscle repair: nitric oxide-mediated activation of muscle satellite cells. Mol Biol Cell 11: 1859-1874.

50. Brenman JE, Chao DS, Xia H, Aldape K, Bredt DS (1995) Nitric oxide synthase complexed with dystrophin and absent from skeletal muscle sarcolemma in Duchenne muscular dystrophy. Cell 82: 743-752.

51. Tidball JG, Lavergne E, Lau KS, Spencer MJ, Stull JT, et al. (1998) Mechanical loading regulates NOS expression and activity in developing and adult skeletal muscle. Am J Physiol Cell Physiol 275: C260-266.

52. Miller KJ, Thaloor D, Matteson S, Pavlath GK (2000) Hepatocyte growth factor affects satellite cell activation and differentiation in regenerating skeletal muscle. Am J Physiol Cell Physiol 278: C174-181.

53. Yamada M, Tatsumi R, Yamanouchi K, Hosoyama T, Shiratsuchi S, et al. (2010) High concentrations of HGF inhibit skeletal muscle satellite cel proliferation in vitro by inducing expression of myostatin: a possible mechanism for reestablishing satellite cell quiescence in vivo. Am J Physiol Cell Physiol 298: C465-476.

54. Yamaguchi A, Ishii H, Morita I, Oota I, Takeda H (2004) mRNA expression of fibroblast growth factors and hepatocyte growth factor in rat plantaris muscle following denervation and compensatory overload. Pflügers Arch 448: 539-546.

55. Tanaka Y, Yamaguchi A, Fujikawa T, Sakuma K, Morita I, et al. (2008) Expression of mRNA for specific fibroblast growth factors associates with that of the myogenic markers MyoD and proliferating cell nuclear antigen in regenerating and overloaded rat plantaris muscle. Acta Physiol (Oxf) 194: 149159

56. Shelmadine B, Cooke M, Buford T, Hudson G, Redd L, et al. (2009) Effects of 28 days of resistance exercise and consuming a commercially available preworkout supplement, NO-Shotgun(R), on body composition, muscle strength and mass, markers of satellite cell activation, and clinical safety markers in males. J Int Soc Sports Nutr 6: 16

57. Tatchum-Talom R, Schulz R, McNeill JR, Khadour FH (2000) Upregulation of neuronal nitric oxide synthase in skeletal muscle by swim training. Am J Physio Heart Circ Physiol 279: H1757-1766.

58. Lima-Cabello E, Cuevas MJ, Garatachea N, Baldini M, Almar M, et al. (2010) Eccentric exercise induces nitric oxide synthase expression through nuclear factor-kB modulation in rat skeletal muscle. J Appl Physiol 108: 575-583.

59. McConell GK, Bradley SJ, Stephens TJ, Canny BJ, Kingwell BA, et al. (2007) Skeletal muscle nNOS $\mu$ protein content is increased by exercise training in humans. Am J Physiol Regul Integr Comp Physiol 293: R821-828.

60. Broholm C, Mortensen OH, Nielsen S, Akerstrom T, Zankari A, et al. (2008) Exercise induces expression of leukaemia inhibitory factor in human skeletal muscle. J Physiol 586: 2195-2201.

61. Metcalf D (2003) The unsolved enigmas of leukemia inhibitory factor. Stem Cells 21: 5-14

62. Hinds MG, Mauer T, Zhang JG, Nicola NA, Norton RS (1997) Resonance assignments, secondary structure and topology of leukaemia inhibitory factor in solution. J Biomol NMR 9: 113-126.

63. Schmelzer CH, Burton LE, Tamony CM (1990) Purification and partia characterization of recombinant human differentiation-stimulating factor Protein Expr Purif 1: 54-62.

64. Kami K, Semba E (1998) Localization of leukemia inhibitory factor and interleukin-6 messenger ribonucleic acids in regenerating rat skeletal muscle. Muscle Nerve 21: 819-822

65. Sakuma K, Watanabe K, Sano M, Uramoto I, Totsuka T (2000) Differentia adaptation of growth and differentiation factor 8/myostatin, fibroblast growth factor 6 and leukemia inhibitory factor in overloaded, regenerating, and denervated rat muscles. Biochim Biophys Acta 1497: 77-88.

66. Gregorevic P, Williams DA, Lynch GS (2002) Effects of leukemia inhibitory factor on rat skeletal muscles are modulated by clenbuterol. Muscle Nerve 25 194-201.

67. Spangenberg EE, Booth FW (2006) Leukemia inhibitory factor restores the hypertrophic response to increased loading in the LIF(-/-) mouse. Cytokine 34 125-130.

68. Austin L, Burgess AW (1991) Stimulation of myoblast proliferation in culture by leukaemia inhibitory factor and other cytokines. J Neurol Sci 101: 193-197

69. Diao Y, Wang X, Wu Z (2009) SOCS1, SOCS3, and PIAS1 promote myogenic differentiation by inhibiting the leukemia inhibitory factor-induced JAK1/STAT1 STAT3 pathway. Mol Cell Biol 29: 5084-5093.

70. Sun L, Ma K, Wang H, Xiao F, Gao Y, et al. (2007) JAK1-STAT1-STAT3, a key pathway promoting proliferation and preventing premature differentiation of myoblasts. J Cell Biol 179: 129-138.

71. Broholm C, Pedersen BK (2010) Leukaemia inhibitory factor--an exerciseinduced myokine. Exerc Immunol Rev 16: 77-85. 
72. McPherron AC, Lawler AM, Lee SJ (1997) Regulation of skeletal muscle mass in mice by a new member TGF-beta superfamily member. Nature 387: 83-90.

73. Lee SJ, McPherron AM (2001) Regulation of myostatin activity and muscle growth. Proc Natl Acad Sci U S A 98: 9306-9311.

74. Wolfman NM, McPherron AC, Pappano WN, Davies MV, Song K, et al. (2003) Activation of latent myostatin by the BMP-1/tolloid family of metalloproteinases. Proc Natl Acad Sci U S A 100: 15842-15846.

75. Zimmers TA, Davies MV, Koniaris LG, Haynes P, Esquela AF, et al. (2002) Induction of cachexia in mice by systemically administerd myostatin. Science 296: $1486-1488$.

76. Langley B, Thomas M, Bishop A, Sharma M, Gilmour S, et al. (2002) Myostatin inhibits myoblast differentiation by down-regulating MyoD expression. J Biol Chem 277: 49831-49840

77. Thomas M, Langley B, Berry C, Sharma M, Kirk S, et al. (2000) Myostatin, a negative regulator of muscle growth, functions by inhibiting myoblast differentiation. J Biol Chem 275: 40235-40243.

78. Yang W, Zhang Y, Li Y, Wu Z, Zhu D (2007) Myostatin induces cyclin D1 degradation to cause cell cycle arrest through a phosphatidylinositol 3-kinase/ AKT/ GSK-3 3 pathway and is antagonized by insulin-like growth factor 1 . J Bio Chem 282: 3799-3808

79. Sakuma K, Yamacuchi A (2011) Inhibitors of myostatin- and proteasomedependent signaling for attenuating muscle wasting. Recent Pat Regen Med 1: 284-298.

80. Tsuchida K (2008) Targeting myostatin for therapies against muscle-wasting disorders. Curr Opin Drug Discov Devel 11: 487-494.

81. Allen DL, Unterman TG (2007) Regulation of myostatin expression and myoblast differentiation by FoxO and SMAD transcription factors. Am J Physiol Cell Physiol 292: C188-199.

82. Trendelenburg AU, Meyer A, Rohner D, Boyle J, Hatakeyama S, et al (2009) Myostatin reduces Akt/TORC1/p70S6K signaling, inhibiting myoblast differentiation and myotube size. Am J Physiol Cell Physiol 296: C1258-1270.

83. Sartori R, Milan G, Patron M, Mammucari C, Blaauw B, et al. (2009) Smad2 and 3 transcription factors control muscle mass in adulthood. Am J Physiol Cell Physiol 296: C1248-1257

84. Lee SJ (2004) Regulation of muscle mass by myostatin. Annu Rev Cell Dev Biol 20: 61-86.

85. Haidet AM, Rizo L, Handy C, Umapathi P, Eagle A, et al. (2008) Longterm enhancement of skeletal muscle mass and strength by single gene administration of myostatin inhibitors. Proc Natl Acad Sci U S A 105: 43184322

86. Hansen J, Brandt C, Nielsen AR, Hoiman P, Whitman M, et al. (2011) Exercise induces a marked increase in plasma follistatin: evidence that follistatin is a contraction-induced hepatokine. Endocrinology 152: 164-171.

87. Jensky NE, Sims JK, Dieli-Conwright CM, Sattler FR, Rice JC, et al. (2010) Exercise does not influence myostatin and follistatin mRNA expression in young women. J Strength Cond Res 24: 522-530.

88. Deldicque L, Atherton P, Patel R, Theisen D, Nielens H, et al. (2008) Effects of resistance exercise with and without creatine supplementation on gene expression and cell signaling in human skeletal muscle. J Appl Physiol 104 371-378.

89. Dennis RA, Przybyla B, Gurley C, Kortebein PM, Simpson P, et al. (2008) Aging alters gene expression of growth and remodeling factors in human skeletal muscle both at rest and in response to acute resistance exercise. Physiol Genomics 32: 393-400.

90. Kim JS, Cross JM, Bamman MM (2005) Impact of resistance loading on myostatin expression and cell cycle regulation in young and older men and women. Am J Physiol Endocrinol Metab 288: E1110-1119.

91. Mascher H, Tannerstedt J, Brink-Elfegoun T, Ekblom B, Gustafsson T, et al. (2008) Repeated resistance training induces different changes in mRNA expression of MAFbx and MuRF-1 in human skeletal muscle. Am J Physiol Endocrinol Metab 294: E43-51.

92. Raue U, Slivka D, Jemiolo B, Hollon C, Trappe S (2006) Myogenic gene expression at rest and after a bout of resistance exercise in young (18-30 yr) and old (80-89 yr) women. J Appl Physiol 101: 53-59.

93. Hulmi JJ, Tannerstedt J, Selänne H, Kainulainen H, Kovanen V, et al. (2009)
Resistance exercise with whey protein ingestion affects mTOR signaling pathway and myostatin in men. J Appl Physiol 106: 1720-1729.

94. Willoughby DS (2004) Effects of heavy resistance training on myostatin mRNA and protein expression. Med Sci Sports Exerc 36: 574-582.

95. Hulmi JJ, Ahtiainen JP, Kaasalainen T, Pollanen E, Hakkinen K, et al. (2007) Postexercise myostatin and activin Ilb mRNA levels: effects of strength training. Med Sci Sports Exerc 39: 289-297.

96. Franchini KG, Torsoni AS, Soares PH, Saad MJ (2000) Early activation of the multicomponent signaling complex associated with focal adhesion kinase induced by pressure overload in the rat heart. Circ Res 87: 558-565.

97. Sakamoto K, Hirshman MF, Aschenbach WG, Goodyear LJ (2002) Contraction regulation of Akt in rat skeletal muscle. J Biol Chem 277: 11910-11917.

98. Cross DAE, Alessi DR, Cohen P, Andjelkovich M, Hemmings BA (1995) Inhibition of glycogen-synthase kinase- 3 by insulin-mediated by proteinkinase-B. Nature 378: 785-789.

99. Manning BD, Tee AR, Logsdon MN, Blenis J, Cantley LC (2002) Identification of the tuberous sclerosis complex-2 tumor suppressor gene product tuberin as a target of the phosphoinositide 3-kinase/Akt pathway. Mol Cell 10: 151-162.

100. Jefferson LS, Fabian JR, Kimball SR (1999) Glycogen synthase kinase-3 is the predominant insulin-regulated eukaryotic initiation factor $2 \mathrm{~B}$ kinase in skeletal muscle. Int J Biochem Cell Biol 31: 191-200.

101. Stitt TN, Drujan D, Clarke BA, Panaro F, Timofeyva Y, et al. (2004) The IGF-I/ $\mathrm{PI} 3 \mathrm{~K} / \mathrm{Akt}$ pathway prevents short article expression of muscle atrophy-induced ubiquitin ligases by inhibiting FOXO transcription factors. Mol Cell 14: 395403.

102. Russell ST, Eley HL, Wyke SM, Tisdale MJ (2008) Involvement of phosphoinositide 3-kinase and Akt in the induction of muscle protein degradation by proteolysis-inducing factor. Biochem J 409: 751-759.

103. Coffey VG, Zhong Z, Shield A, Canny BJ, Chibalin AV, et al. (2006) Early signaling response to divergent exercise stimuli in skeletal muscle from welltrained humans. FASEB J 20: 190-192.

104. Léger B, Cartoni R, Praz M, Lamon S, Dériaz O, et al. (2006) Akt signaling through GSK-3ß, mTOR and Foxo1 is involved in human skeletal muscle hypertrophy and atrophy. J Physiol 576: 923-933.

105. Mascher H, Tannerstedt J, Brink-Elfegoun T, Ekblom B, Gustafsson T, et al (2008) Repeated resistance exercise training induces different changes in mRNA expression of MAFbx and MuRF-1 in human skeletal muscle. Am J Physiol Endocrinol Metab 294: E43-51.

106. Mayhew DL, Kim JS, Cross JM, Ferrando AA, Bamman MM (2009) Translational signaling responses preceding resistance training-mediated myofiber hypertrophy in young and old humans. J Appl Physiol 107: 1655 1662.

107.Dunn SE, Burns JL, Michel RN (1999) Calcineurin is required for skeletal muscle hypertrophy. J Biol Chem 274: 21908-21912.

108. Michel RN, Chin ER, Chakkalakal JV, Eibl JK, Jasmin BJ (2007) $\mathrm{Ca}^{2+}$ calmodulin-based signaling in the regulation of the muscle fiber phenotype and its therapeutic potential via modulation of utrophin $A$ and myostatin expression. Appl Physiol Nutr Metab 32: 921-929.

109. Friday BB, Mitchell PO, Kegley KM, Pavlath GK (2003) Calcineurin initiates skeletal muscle differentiation by activating MEF2 and MyoD. Differentiation 71: 217-227.

10. Al-Shanti N, Stewart CE (2009) $\mathrm{Ca}^{2+} /$ calmodulin-dependent transcriptiona pathways: potential mediators of skeletal muscle growth and development Biol Rev Camb Philos Soc 84: 637-652.

111. Sakuma K, Nakao R, Aoi W, Inashima S, Fujikawa T, et al. (2005) Cyclosporin A treatment upregulates Id 1 and Smad3 expression and delays skeletal muscle regeneration. Acta Neuropathol 110: 269-280.

112. Sakuma K, Yamaguchi A (2010) The functional role of calcineurin in hypertrophy, regeneration, and disorders of skeletal muscle. J Biomed Biotechnol 2010: 721219

113. Delling U, Tureckova J, Lim HW, De Windt LJ, Rotwein P, et al. (2000) A calcineurin-NFATc3- dependent pathway regulates skeletal muscle differentiation and slow myosin heavy-chain expression. Mol Cell Biol 20: $6600-6611$

114. Michel RN, Dunn SE, Chin ER (2004) Calcineurin and skeletal muscle growth. Proc Nutr Soc 63: 341-349. 
115. Miyazaki M, Hitomi Y, Kizaki T, Ohno H, Katsumura T, et al. (2006) Calcineurinmediated slow-type fiber expression and growth in reloading condition. Med Sci Sports Exerc 38: 1065-1072.

116. Oishi Y, Ogata T, Yamamoto KI, Terada M, Ohira T, et al. (2008) Cellular adaptations in soleus muscle during recovery after hindlimb unloading. Acta Physiol (Oxf) 192: 381-395.

117. Talmadge RJ, Otis JS, Rittler MR, Garcia ND, Spencer SR, et al. (2004) Calcineurin activation influences muscle phenotype in a muscle-specific fashion. BMC Cell Biol 5: 28

118. Hennebry A, Berry C, Siriett V, O'Callaghan P, Chau L, et al. (2009) Myostatin regulates fiber-type composition of skeletal muscle by regulating MEF2 and MyoD gene expression. Am J Physiol Cell Physiol 296: C525-534.

119. Sakuma K, Akiho M, Nakashima H, Nakao R, Hirata M, et al. (2008) Cyclosporin A modulates cellular localization of MEF2C protein and blocks fiber hypertrophy in the overloaded soleus muscle of mice. Acta Neuropathol 115: 663-674.

120. Hinits $Y$, Hughes SM (2007) Mef2s are required for thick filament formation in nascent muscle fibres. Development 134: 2511-2519.

121.Potthoff MJ, Arnold MA, McAnally J, Richardson JA, Bassel-Duby R, et al. (2007) Regulation of skeletal muscle sarcomere integrity and postnatal muscle function by Mef2c. Mol Cell Biol 27: 8143-8151.

122. Garcia-Roves PM, Jones TE, Otani K, Han DH, Holloszy JO (2005) Calcineurin does not mediate exercise-induced increase in muscle GLUT4. Diabetes 54 624-628.

123. Grondard C, Biondi O, Pariset C, Lopes P, Deforges S, et al. (2008) Exerciseinduced modulation of calcineurin activity parallels the time course of myofibre transitions. J Cell Physiol 214: 126-135.

124. Wu H, Rothermel B, Kanatous S, Rosenberg P, Naya FJ, et al. (2001) Activation of MEF2 by muscle activity is mediated through a calcineurindependent pathway. EMBO J 20: 6414-6423.

125.Lamas L, Aoki MS, Ugrinowitsch C, Campos GE, Regazzini M, et al. (2010) Expression of genes related to muscle plasticity after strength and power training regimens. Scand J Med Sci Sports 20: 216-225.

126. Treisman $\mathrm{R}$ (1987) Identification and purification of a polypeptide that binds to the $\mathrm{c}$-fos serum response element. EMBO J 6: 2711-2717.

127. Muscat GE, Gustafson TA, Kedes L (1988) A common factor regulates skeletal and cardiac alpha-actin gene transcription in muscle. Mol Cell Biol 8: 4120-4133.

128. Ernst H, Walsh K, Harrison CA, Rosenthal N (1991) The myosin light chain enhancer and the skeletal actin promoter share a binding site for factors involved in muscle-specific gene expression. Mol Cell Biol 11: 3735-3744.

129. Pipes GC, Creemers EE, Olson EN (2006) The myocardin family of transcriptional coactivators: versatile regulators of cell growth, migration, and myogenesis. Genes Dev 20: 1545-1556.

130. Charvet C, Houbron C, Parlakian A, Giordani J, Lahoute C, et al. (2006) New role for serum response factor in postnatal skeletal muscle growth and regeneration via the interleukin 4 and insulin-like growth factor 1 pathways. Mol Cell Biol 26: 6664-6674

131.Lange S, Xiang F, Yakovenko A, Vihola A, Hackman P, et al. (2005) The kinase domain of titin controls muscle gene expression and protein turnover Science 308: 1599-1603.

132. Arai A, Spencer JA, Olson EN (2002) STARS, a striated muscle activato of Rho signaling and serum response factor-dependent transcription. J Biol Chem 277: 24453-24459.

133. Kuwahara K, Barrientos T, Pipes GC, Li S, Olson EN (2005) Muscle-specific signaling mechanism that links actin dynamics to serum response factor. Mol Cell Biol 25: 3173-3181.

134. Puchner EM, Alexandrovich A, Kho AL, Hensen U, Schäfer LV, et al. (2008) Mechanoenzymatics of titin kinase. Proc Natl Acad Sci U S A 105: 1338513390.

135. Ochala J, Gustafson AM, Diez ML, Renaud G, Li M, et al. (2011) Preferential skeletal muscle myosin loss in response to mechanical silencing in a novel rat intensive care unit model: underlying mechanisms. J Physiol 589: 2007-2026.

136. Spencer JA, Eliazer S, Ilaria Jr RL, Richardson JA, Olson EN (2000) Regulation of microtubule dynamics and myogenic differentiation by MURF, a striated muscle RING-finger protein. J Cell Biol 150: 771-784.
137. Miralles F, Posern G, Zaromytidou Al, Treisman R (2003) Actin dynamics control SRF activity by regulation of its coactivator MAL. Cell 113: 329-342.

138. Kuwahara K, Teg Pipes GC, McAnally J, Richardson JA, Hill JA, et al. (2007) Modulation of adverse cardiac remodeling by STARS, a mediator of MEF2 signaling and SRF activity. J Clin Invest 117: 1324-1334.

139. Lamon S, Wallace MA, Léger B, Russell AP (2009) Regulation of STARS and its downstream targets suggest a novel pathway involved in human skeletal muscle hypertrophy and atrophy. J Physiol 587: 1795-1803.

140. Allen DL, Sartorius CA, Sycuro LK, Leinwand LA (2001) Different pathways regulate expression of the skeletal myosin heavy chain genes. J Biol Chem 276: 43524-43533.

141. Puigserver P, Wu Z, Park CW, Graves R, Wright M, et al. (1998) A coldinducible coactivator of nuclear receptors linked to adaptive thermogenesis. Cell 92: 829-839.

142. Scarpulla RC (2008) Transcriptional paradigms in mammalian mitochondria biogenesis and function. Physiol Rev 88: 611-638.

143. Russell AP, Feilchenfeldt J, Schreiber S, Praz M, Crettenand A, et al. (2003) Endurance training in humans leads to fiber type-specific increases in levels of peroxisome proliferator-activated receptor- gamma coactivator-1 and peroxisome proliferator-activated receptor-alpha in skeletal muscle. Diabetes 52: $2874-2881$

144. Aoi W, Naito Y, Mizushima K, Takanami Y, Kawai Y, et al. (2010) The microRNA miR-696 regulates PGC-1a in mouse skeletal muscle in response to physical activity. Am J Physiol Endocrinol Metab 298: E799-806.

145. Sandri M, Lin J, Handschin C, Yang W, Arany ZP, et al. (2006) PGC-1alpha protects skeletal muscle from atrophy by suppressing $\mathrm{FoxO} 3$ action and atrophy-specific gene transcription. Proc Natl Acad Sci U S A 103: 1626016265

146. Brault JJ, Jespersen JG, Goldberg AL (2010) Peroxisome proliferatoractivated receptor gamma coactivator 1alpha or 1 beta overexpression inhibit muscle protein degradation, induction of ubiquitin ligases, and disuse atrophy. J Biol Chem 285: 19460-19471.

147. Baker DJ, Betik AC, Krause DJ, Hepple RT (2006) No decline in skeletal muscle oxidative capacity with aging in long-term calorically restricted rats: effects are independent of mitochondrial DNA integrity. J Gerontol A Biol Sci Med Sci 61: 675-684.

148. Crunkhorn S, Dearie F, Mantzoros C, Gami H, da Silva WS, et al. (2007) Peroxisome proliferator activator receptor gamma coactivator-1 expression is reduced in obesity: potential pathogenic role of saturated fatty acids and p38 mitogen-activated protein kinase activation. J Biol Chem 282: 15439-15450.

149. Roberts-Wilson TK, Reddy RN, Bailey JL, Zheng B, Ordas R, et al. (2010) Calcineurin signaling and PGC-1alpha expression are suppressed during muscle atrophy due to diabetes. Biochim Biophys Acta 1803: 960-967.

150. Fuster G, Busquets S, Ametller E, Olivan M, Almendro V, et al. (2007) Are peroxisome proliferator-activated receptors involved in skeletal muscle wasting during experimental cancer cachexia? Role of beta2-adrenergic agonists. Cancer Res 67: 6512-6519.

151. Dobrowolny G, Aucello M, Rizzuto E, Beccafico S, Mammucari C, et al. (2008) Skeletal muscle is a primary target of SOD1G93A-mediated toxicity. Cell Metab 8: 425-436.

152. Handshin C, Chin S, Li P, Liu F, Maratos-Flier E, et al. (2007) Skeletal muscle fiber-type switching, exercise intolerance, and myopathy in PGC-1alpha muscle-specific knock-out animals. J Biol Chem 282: 30014-30021.

153. Wenz T, Rossi SG, Rotundo RL, Spiegelman BM, Moraes CT (2009) Increased muscle PGC-1alpha expression protects from sarcopenia and metabolic disease during aging. Proc Natl Acad Sci U S A 106: 20405-20410.

154. Hanai J, Cao P, Tanksale P, Imamura S, Koshimizu E, et al., (2007) The muscle- specific ubiquitin ligase atrogin-1/MAFbx mediates statin-induced muscle toxicity. J Clin Invest 117: 3940-3951.

155. Cai D, Frantz JD, Tawa NE Jr, Melendez PA, Oh BC, et al. (2004) IKKbeta/NFkappaB activation causes severe muscle wasting in mice. Cell 119: 285-298.

156. Hasselgren PO (2007) Ubiquitination, phosphorylation, and acetylation-triple threat in muscle wasting. J Cell Physiol 213: 679-689.

This article was originally published in a special issue, Muscle Hypertrophy handled by Editor(s). Dr. Jennifer A. Bunn, Campbell University, USA 